\title{
Notes on the vocalizations of Eastern Double-collared Sunbird (Cinnyris mediocris)
}

Peter Boesman

In the following we briefly analyze and compare voice of the different races of Eastern Double-collared Sunbird (Cinnyris mediocris). We also try to quantify the extent of any vocal differences using the criteria proposed by Tobias et al. (2010), as a support for taxonomic review. We have made use of sound recordings available on-line from Xeno Canto (XC) and Macaulay Library (ML).

nominate $(n=7)$ : song seemingly is a very rapid twinkling series of notes (rather monotonous at a fairly stable high pitch), sometimes introduced with a few separate notes or a chatter. Some examples:
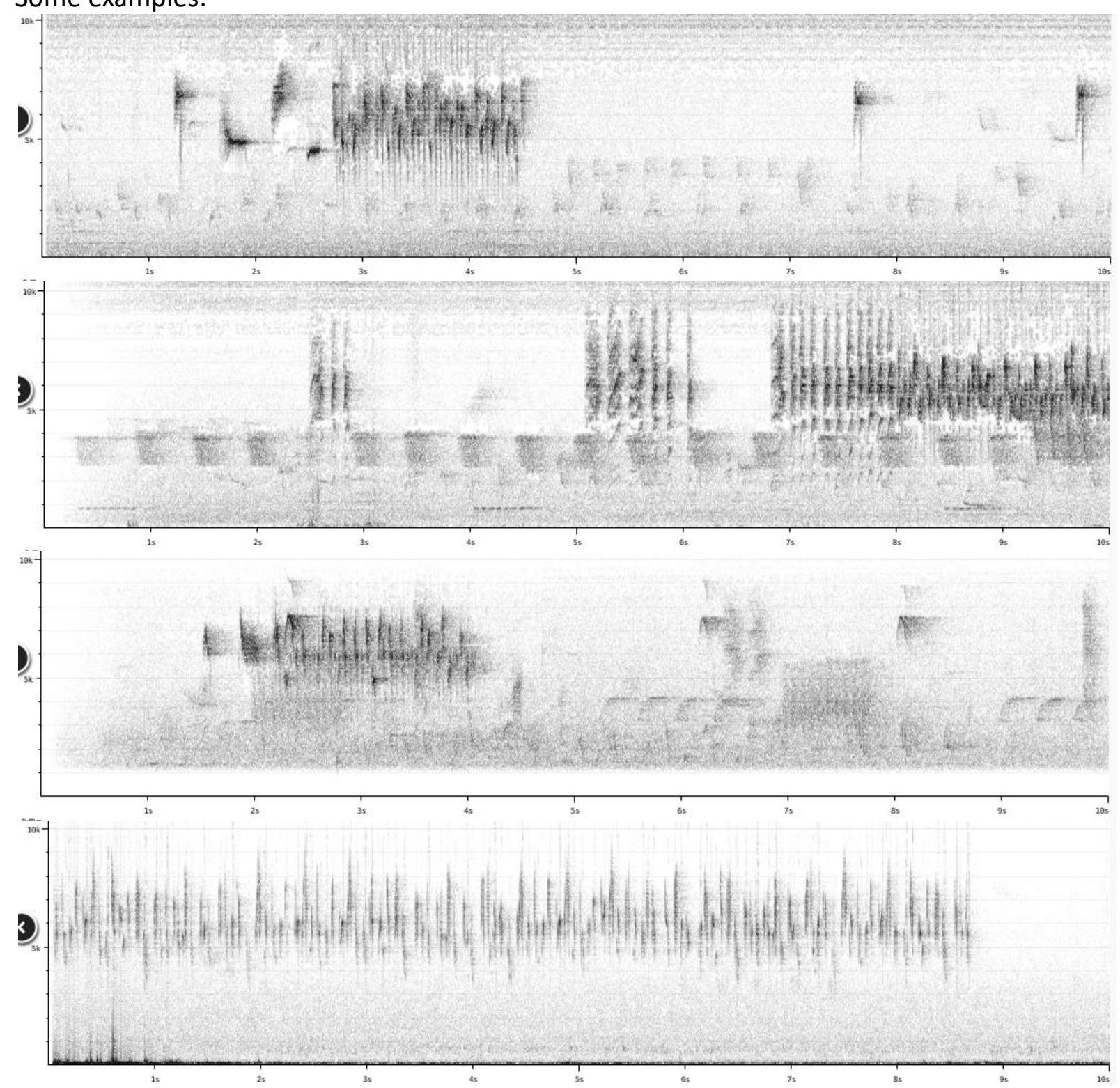

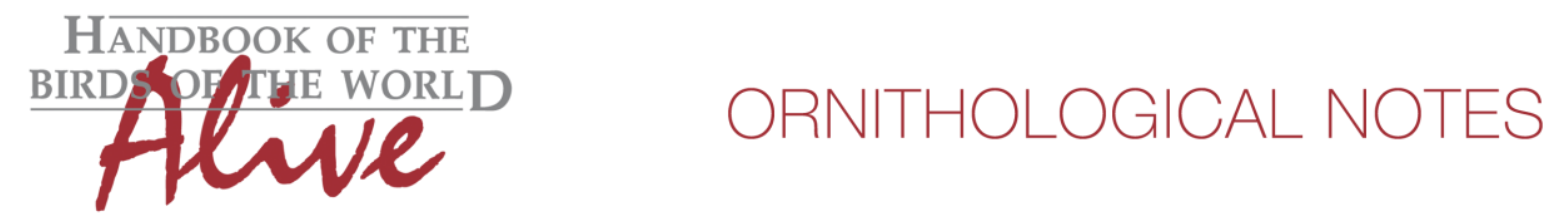

usumbaricus ( $n=1$, not sure if this ID is reliable, XC119515)

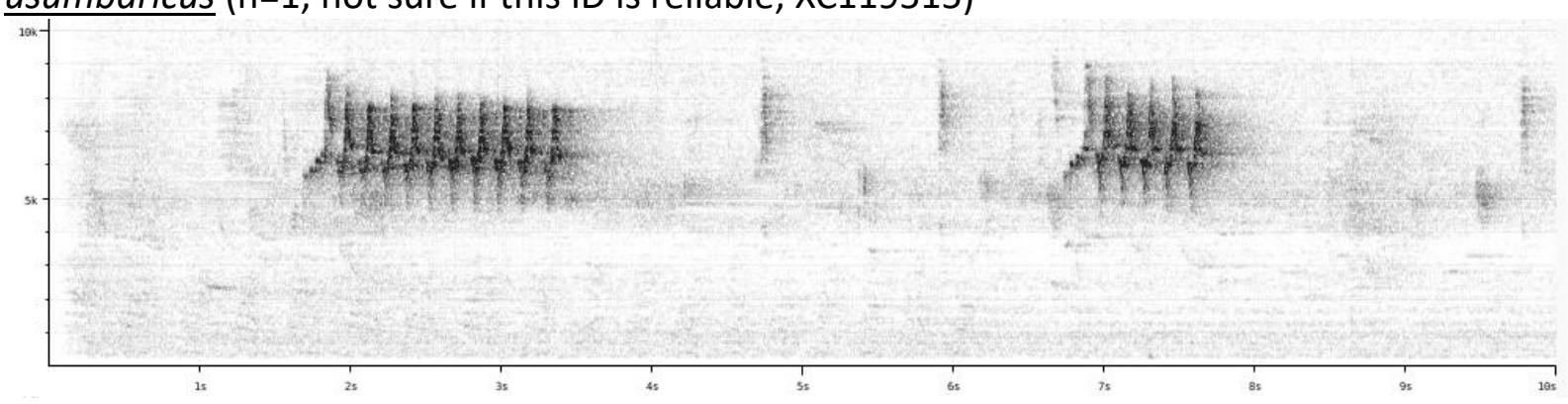

fuelleborni ( $n=6)$ : song is a long varied warble of squeaky, scratchy and more melodious whistles, sometimes introduced with some separate notes or chatter. Pace variable with slower and faster sequences.

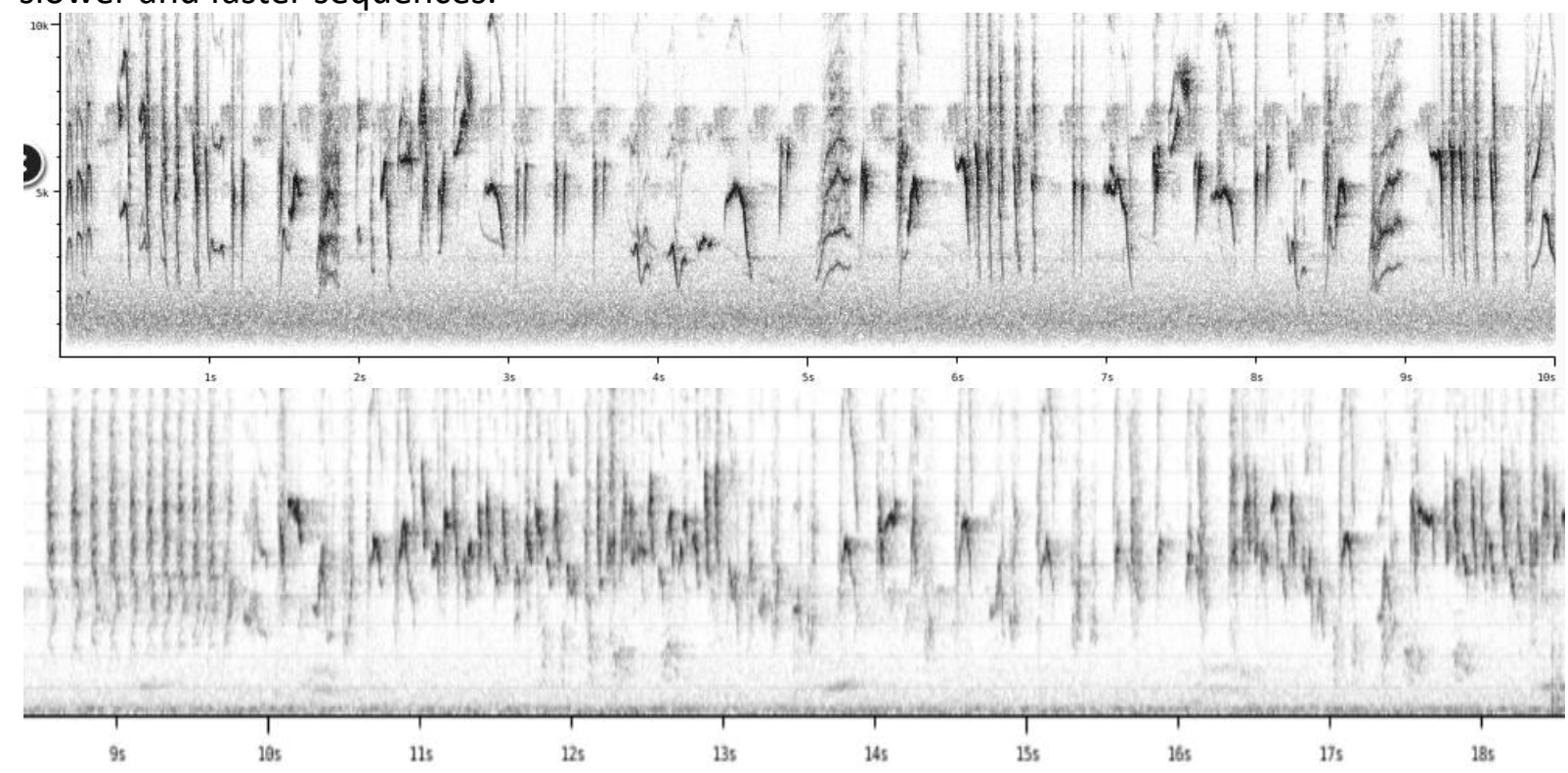

It would seem that nominate and fuelleborni have both a characteristic song which shows important differences: the latter has a higher number of different notes (2), longer notes (excl. intro notes)(2) which reach lower frequencies (2), and a slower average pace (2). When applying Tobias criteria, this would lead to a total vocal score of 4.

Without the availability of additional recordings for usumbaricus, the very different single recording may either be a mistake, a vocalization other than true song or a genuinely different song (with short well-separated phrases (3) of identical notes repeated (3)). It is clear that more recordings are needed here.

This note was finalized on 25th April 2016, using sound recordings available on-line at that moment. We would like to thank in particular the sound recordists who placed their recordings for this species on XC: James Bradley, Frank Lambert, Catriona Leven, David Moyer, Rory Nefdt, Myles North, Bram Piot and Martin St-Michel. 


\section{References}

Tobias, J.A., Seddon, N., Spottiswoode, C.N., Pilgrim, J.D., Fishpool, L.D.C. \& Collar, N.J. (2010). Quantitative criteria for species delimitation. Ibis 152(4): 724-746.

\section{Recommended citation}

Boesman, P. (2016). Notes on the vocalizations of Eastern Double-collared Sunbird (Cinnyris mediocris). HBW Alive Ornithological Note 338. In: Handbook of the Birds of the World Alive. Lynx Edicions, Barcelona. (retrieved from http://www.hbw.com/node/1252797 on 25 October 2016). 